\title{
O lugar da arte no currículo escolar: uma análise dos Programas Experimentais para o Curso Primário e Pré-primário no Paraná (1950-1952)
}

\author{
Rossano Silva*
}

\begin{abstract}
Resumo
O presente artigo explora o papel dado a arte nos Programas experimentais para o Curso Primário e Préprimário, implantados no Estado do Paraná pelo educador paranaense Erasmo Pilotto. O recorte da pesquisa explora os anos de 1950 a 1952, período que corresponde à atuação do intelectual no cargo de Secretário Estadual de Educação e Cultura do Paraná. Nessa posição, Pilotto pode aliar as ações realizadas no campo educacional e artístico, integrando a arte e a educação e enfatizando o papel da primeira no que chamou de formação de uma cultura geral da criança e do professor, concepção que foi tônica de suas propostas pedagógicas, sistematizada em diversas obras escritas entre as décadas de 1940 e 1980. Para alcançar os objetivos propostos, esta investigação se apoiará na teoria praxiológica de Bourdieu que permitirá analisar a interação das ações de Pilotto nos diferentes campos: educacional, artístico e político.

Palavras Chave: História das Práticas Educacionais; História da Educação; Ensino de Arte; Currículo Escolar.
\end{abstract}

\section{The place of art in school curriculum: an experimental analysis of programs for pre-primary education in} primary at Paraná (1950-1952)

\begin{abstract}
This article explores the role given to Arts in experimental programs for Primary and Pre-Primary school courses, developed in the State of Paraná by the Paraná's educator Erasmus Pilotto. This research pictures the period of 1950 to 1952, which corresponds to Pilotto's action as Paraná's Secretary of State for Education and Culture Affairs. In this position, Pilotto could combine activities in both educational and artistic fields by emphasizing the role of Arts in the construction of children and teacher general culture, conception that was the main focus of his pedagogical proposals, presented in several of his works written during the years of 1940 to 1980. To achieve its proposed objectives, this investigation will rely itself in the Bourdieu's theory of practice that will allow an analysis of the interaction from Pilloto's actions in many fields such as: educational, artistic and political.

Keywords: History of Educational Practices; History of Education; Art Teaching; School Curriculum.

\section{Introdução}

O presente artigo pretende explorar o papel dado à arte no currículo escolar, analisando as disciplinas de desenho e trabalhos manuais dos Programas Experimentais para o Ensino Préprimário e Primário desenvolvidos pelo educador paranaense Erasmo Pilotto (Rebouças, 1910 Curitiba, 1992), considerado pela história da educação como um dos principais articuladores, no Paraná, do Movimento pela Escola Nova. O recorte da pesquisa privilegia os anos de 1950 a 1952, correspondentes ao período de atuação do intelectual no cargo Secretário Estadual de Educação e Cultura do Paraná.

Nessa posição, Pilotto pôde aliar as ações realizadas no campo educacional e artístico, integrando a arte e a educação e enfatizando o papel da primeira no que chamou de formação de uma cultura geral, concepção que foi tônica em suas propostas pedagógicas, sistematizada em diversas

obras escritas entre as décadas de 1940 até 1980.

Para alcançar os objetivos propostos, esta investigação se apoiará na teoria praxiológica de Bourdieu (1994, 1996, 2004 e 2006) - concepção teórica que associa campo, habitus e capital, resultando numa determinada prática associada a uma análise do mundo social que rompe com a abordagem da fenomenologia e do objetivismo. A prática, ou seja, o que realmente se efetiva num determinado tempo histórico e social, não depende apenas do sujeito no sentido de uma escolha individual, mas leva em conta o campo como um todo. O campo como elemento constituinte da sociedade pode ser interpretado como aquilo que é oferecido como possibilidade ao indivíduo, que, por seu turno, conforme a quantidade de "capital" disponível, pode assumir ou não posições de poder e prestígio nas diferentes esferas de atuação.

Pode-se considerar que, na esfera intelectual paranaense, Erasmo Pilotto em grande medida personifica os aspectos sublinhados por Bourdieu.
\end{abstract}

*Endereço eletrônico: rossano.silva @ufpr.br 
De fato, Pilotto era reconhecido enquanto uma autoridade no campo artístico e educacional devido tanto ao capital cultural herdado de sua família, em grande parte ligada ao magistério , bem como ao capital social e simbólico acumulado pelas suas relações e ações na área da educação e artes.

No campo educacional, atuou na Escola de Professores entre os anos de 1933 a 1947, instituição na qual foi aluno, promovendo a divulgação de seu pensamento ligado ao Movimento da Escola Nova e priorizando a cultura e a arte como princípios formadores do professor. Como aluno da instituição, criou conjuntamente com seus colegas o Centro de Cultura Pedagógica (1928-29). A partir dos estudos realizados no Centro, Pilotto recusa os métodos instituídos na Escola de Professores preconizados pelas teorias de Herbart e traça seus estudos a partir da leitura de Azevedo, Gentile, Montessori, Peslatozzi e Tolstoi, autores com os quais manteve interlocução por toda sua produção intelectual.

Sua atuação no campo artístico inicia-se com a fundação do Centro de Cultura Filosófica (1927-1930), junto a um grupo interessado em debater a modernização das artes e da literatura em Curitiba. Participou da fundação e criação da Sociedade de Cultura Artística Brasílio Itiberê SCABI (1944-1976), atuando com o grupo de intelectuais e artistas ligados à instituição em seus projetos, como o da realização de concertos populares de música, bem como da criação do Salão Paranaense de Belas Artes (1944) e da fundação da Escola de Música e Belas Artes do Paraná (1948). Sua inserção no campo literário e jornalístico ocorre com a publicação de ensaios sobre artistas e escritores paranaenses, com a participação na imprensa nos jornais Diário da Tarde e O Dia, nos quais publicou crônicas e críticas de arte, e também na revista Joaquim, na qual, além de publicar ensaios e entrevistas com artistas, atuou como diretor. Essas ações culminaram, por meio das relações com o campo político, em sua nomeação ao cargo de Secretário da Educação e Cultura do Paraná, no período de 1949 e 1951.

\section{Os Programas Experimentais}

Os Programas Experimentais foram implantados em 1950 com o intuito de servir de modelo pedagógico aos Cursos Normais Regionais, bem como, para implementar mudanças nas práticas educacionais dos Grupos Escolares já existentes. Sua concepção foi trazida das experiências educacionais de Pilotto, no magistério na Escola de Professores (1933-1947) e no Instituto Pestalozzi (1943-1945). Os Programas, nas palavras do intelectual, não seriam a Escola Nova planejada anteriormente, mas buscariam adaptar suas concepções à realidade educacional imposta: "sabendo que seria impossível uma implantação da Escola Nova, dadas às condições de nosso desenvolvimento, formulei, então resumindo minhas aulas de metodologia na Escola Normal" (PILOTTO, 2004, p. 75).

Ao apresentar os Programas Experimentais no livro A educação é um Direito de Todos (1952), o intelectual faz críticas indiretas às reformas instituídas por Lysimaco Ferreira da Costa e ao Regimento Interno e Programa para os grupos escolares do Estado. Para Pilotto existe uma:

[...] tradição de idealismo na cátedra de nossas Escolas Normais que só se interrompeu em poucos momentos, em que a mediocridade nelas fez praça, - num parêntesis ocorrido por obra de interesses e egocentrismos de dirigentes políticos, há mais de 20 anos [...] A nossa critica não se dirige aos mestres nem ao rendimento das escolas. Dirige-se aos padrões de trabalho $e$ às rotinas que lhe foram determinadas. Faltou sempre uma força permanentemente criadora, atualizando sempre $e$ aproveitando as conquistas da organização $e$ da ciência para a educação sempre melhor da infância [...] Permito-me dizer que a educação nas cidades, entre nós, foi um excelente organismo, sem cabeça. Toda a possibilidade atualizadora e criadora foi considerada suspeita. (PILOTTO, 1952, p. 65).

Na obra A Educação no Paraná: Síntese sobre o ensino público elementar e médio (1954), o intelectual realiza um levantamento sobre o ensino paranaense desde a emancipação do Estado da comarca de São Paulo, em 1853 até sua gestão na Secretaria de Educação e Cultura - SEC. Sobre a reforma de 1940, efetivada pelo decreto 9.592, essa é considerada por Pilotto como um molde que impede os professores de criarem em suas rotinas escolares. Outra crítica destinada ao regimento vem do fato de ignorarem os cursos pré-primários, seja pelo fato da formação dos professores não contemplar esse ponto, ou dos regimentos não indicarem nenhuma rotina. 
Em nossa apreciação particular, a Diretoria de Educação entrara em uma fase conservadora. Enquanto as Escolas Normais do Estado e, em particular, a de Curitiba, realizavam uma ampla e até inquieta pregação renovadora, a Diretoria de Educação fechava-se numa atitude conservadora [...] E, assim, aqueles elementos de exceção, uma vez ou outra, conseguiram estimular medidas e impulsos renovadores. A linha geral, porém, era conservadora (PILOTTO, 1954, p 69, grifo nosso).

É possível que Pilotto ao citar os "elementos de exceção", estivesse se autorreferenciando, pois nesse período sua atuação se dava diretamente na Escola de Professores, no cargo de assistente técnico, bem como, na década de 1940, realizou diversas experiências educacionais como as Exposições de Arte Infantil e o Instituto Pestalozzi. Para o intelectual, nas Escolas Normais estava presente o "espírito renovador", como se pode perceber ao comentar a educação no Paraná após 1948.

[...] assumimos a direção da, já então, Secretaria de Educação e Cultura. Levamos, para lá, o espírito das Escolas Normais. E procuramos por em ação, nos pontos vitais, a elite de professores que as Escolas Normais vinham formando, dentro do novo espírito. Elaboramos novos programas para as escolas primárias $e$ jardins da infância. $O$ que as Escolas Normais pregavam, condensava-se em estatuto legal (PILOTTO, 1954, p. 70).

Na obra citada, Pilotto constrói uma memória da educação do Paraná, excluindo e minimizando conflitos e opositores, construindo uma linha direta de evolução das reformas até chegarem à sua gestão. E como um dos pontos altos dessa memória educacional, figura a implantação dos Programas Experimentais para o Ensino Primário e Pré-Primário.

Para a implantação dos Programas Experimentais, Pilotto contou com uma estratégia baseada em três pontos: 1) colocar os diretores dos grupos escolares como colaboradores para o cumprimento integral dos programas, enfatizando a sua adequação aos padrões definidos pelo Ministério da Educação; 2) realizar a formação dos professores nas atividades de desenho, canto, trabalhos manuais e educação física, bem como, conjuntamente à Associação Montessori, fornecer a formação para as professoras do pré-primário, ações que seriam centralizadas no Instituto de Educação (antiga Escola de Professores); 3) Trazer "a elite de professores" que as Escolas Normais formaram para agirem como líderes dos demais professores, bem como, trazer artistas e intelectuais para atuarem nessa ampla formação do magistério. Com essa estratégia, Pilotto busca testar sua metodologia de ensino e se articular nacionalmente a partir da adequação de seu modelo pedagógico às diretrizes do Ministério da Educação, além de promover seus colaboradores colocados como a "elite" educacional do Estado.

Para o ensino pré-primário, Pilotto afirma ter moldado seu plano seguindo a orientação de Robert Hill Lane, no estudo Introdução a uma filosofia da educação, publicado nos Anais de Instrução primária de Montevidéu, em dezembro de 1943. Conforme Pilotto, o plano de Lane sugere como princípio de ação experiências nos diferentes campos da vida social da criança, nas ciências naturais, nas artes, na estética e nas habilidades e adestramentos. Ao investigar as origens do artigo de Lane, Botelho (2011, p. 56) identifica o autor como Assistente Superintendente de Escolas de Los Angeles. Conforme a autora, Lane tinha uma clara adesão à concepção de Dewey.

Assim como em Dewey, Pilotto concebe a experiência como fundamento, partindo da situação empírica para o pensamento. Conforme observamos nas propostas elaboradas e/ou sistematizadas por Lane, as atividades relacionadas às artes são um fundamento para o ensino pré-primário, sendo mantidas como essência dos Programas Experimentais. Pilotto afirma que preferiu assumir essa orientação a adotar as orientações da pedagogia montessoriana, que exigiriam um alto apuro técnico do mestre, embora, como constatamos, a SEC tenha promovido durante sua gestão diversos encontros para a formação de educadores nas propostas de Montessori.

A aproximação de Pilotto com as teorias de Lane é debatida por Botelho (2011), que afirma que a opção do intelectual em utilizar esse autor estaria ligada mais a relativação de suas teorias frente a realidade heterogênea dos diversos contextos socioeconomicos paranaenses. Se inicialmente em sua Escola Serena existe um diálogo entre os princípios caros ao Movimento pela Escola Nova, inspirados na pedagogia rousseauniana, na filosofia 
espiritualista de Gentile, e na teoria de Dewey, seu período como Secretário o faz rever suas concepções adotando uma pedagogia diferencial. Para Botelho, essa relativização explicaria a apropriação da teoria de Lane, e por consequência a de Dewey, se daria de modo mais circunstancial dadas as orientações do INEP e dada a realidade educacional do Paraná.

Concordamos com a autora sobre a aproximação de Pilotto com Dewey através da leitura de Lane, bem como o conceito de experiência que apesar de não ser referenciado no livro Prática da Escola Serena (1946), está claramente colocado nas propostas pedagógicas da obra em questão. Mas, também evidenciamos a posição de Vieira (2006, p.5) que afirma que o projeto intelectual de Pilotto difere da base da filosofia pragmática que permeou boa parte dos projetos do Movimento pela Escola Nova no contexto nacional. Assim, apesar de manter as referências do INEP para o Programas Experimentais, Pilotto traz as referências de sua formação intelectual para compor seu quadro conceitual.

Para os Programas Experimentais para o Ensino Primário, o intelectual afirma que deixou a proposta de Lane, pois ela representaria um choque de realidade muito grande para as rotinas instaladas nos grupos escolares pelo regulamento então vigente. Assim, apesar da concessão, Pilotto afirma que as recomendações dadas nos programas advêm de uma síntese de seus cursos de metodologia, ministrados na Escola de Professores, sendo valorizados os aspectos práticos em detrimento aos teóricos. Afirma ainda que os programas de canto e educação física viriam do INEP. Devemos lembrar que Pilotto concebe os Programas Experimentais para a categoria de professores que, na sua opinião, não teriam o espírito de líderes educacionais, dessa forma deveriam agir com instruções precisas aos educadores em "campo".

Abordaremos a seguir como cada Programa Experimental procurou desenvolver as atividades relacionadas à formação artística e estética, especialmente tendo em foco as atividades de desenho e trabalhos manuais ${ }^{1}$.

\section{O desenho e os trabalhos manuais nos Programas Experimentais}

Os Programas Experimentais para o Jardim da Infância (1950), constituem-se em um documento com 22 páginas dividido em: Programas de Experiências e Programas de Educação Sensorial e da Atenção. Os Programas Experimentais seguem a proposta de campos definidos por Lane. No campo da estética tem-se as seguintes descrições dos meios e utilização.

[Meios] Trabalhar com argila; pintar com tinta de parede; arrumar flores; cantar; bailar e saltar por música; inventar danças originais. [utilização] Arrumar os vasos de cor de acordo com o arco-íris; sair ao jardim depois da chuva; olhar as nuvens e a sombras; misturar cores de tintas brilhantes; soprar bolhas de sabão; brincar com prismas; estudar e discutir gravuras; escutar a orquestra ou a banda; colecionar gravuras para o uso pessoal; compor cantos simples; experimentar o som de diferentes metais, madeiras e cristais; aprender o nome dos instrumentos musicais; reproduzir as experiências mediante a pintura; modelar em argila animais domésticos da escola; ver quadros de pintura e ouvir músicas; escutar o piano, o rádio e a vitrola. (SEC, 1950, p. 7, grifo nosso).

Além das propostas de expressão, havia também propostas que visavam uma educação estética e dos sentidos através da observação e contemplação da natureza e de objetos artísticos. Deve-se lembrar que no tocante ao contato da criança com objetos de arte produzidos por adultos, não eram práticas predominantes nas teorias de ensino de arte ligadas à livre-expressão ${ }^{2}$, como nas propostas desenvolvidas por Mário de Andrade, bem como, nas de Educação pela Arte de Herbert $\operatorname{Read}^{3}$, que previam apenas para os adolescentes o contato com a produção artística.

No campo das Habilidades tem-se as de natureza estética, que são definidas como o: "Dominar todo o referente às experiências musicais e artísticas pessoais." (SEC, 1950, p. 9). Como fontes de experiências estéticas, os Programas sugerem que sejam criados espaços educativos como

Centro de arte: pincéis, tintas, papel para pintura, cavaletes [...] Mesa de Modelagem, argila, modelos feitos pelos alunos [...] Mesa para Música, instrumentos musicais, tambores, flautas [...] Biblioteca: uma mesa equipada com livros de gravura, revistas 
[...] Teatrinho de fantoches [...] (SEC, 1950, p. 9-10).

As descrições do programa se assemelham às da proposta realizada por Pilotto no Instituto Pestalozzi, com a criação de diversos espaços educativos, pensados para a experiência da criança. Espaços necessários para desenvolver sua "escola serena", embora a concepção do espaço educativo, que muitas vezes viria mais da iniciativa dos grupos, do que propriamente de ações governamentais, tenha levantado críticas às ideias de Pilotto. Na matéria intitulada A Escola Pestalozzi que Fracassou temos uma crítica endereçada à criação de um espaço mais educativo.

A Secretaria da educação quer nas Escolas ambiente de alegria, tapetes e flores a custa das professoras, devendo estas também comprar de seu bolso até o programa letivo. $O$ governo anuncia saldos positivos orçamentários, difusão do ensino e um "Paraná Maior", mas parece que falta dinheiro ao menos do miúdo, na Secretaria da Educação, pois as ordens que existem é para as professoras lançarem mão dos próprios vencimentos no sentido de darem às escolas uma expressão de alegria e de comunicabilidade [...] Tais idéias surgiram no dr. Erasmo Pilotto desde o tempo da sua Pestalozzi que afinal fracassou. (DIÁRIO DA TARDE, 17 mar. 1950, p. 1 e 6).

$\mathrm{Na}$ continuidade há críticas à posição do governo, em especial da SEC, por exigir que os docentes utilizassem seus vencimentos para bancar a Escola Serena de Pilotto. Não é uma crítica propriamente aos métodos preconizados, mas à forma de financiá-los, pois nesse momento o Estado faz uma série de investimentos em infraestrura viária e de saúde, o que, para a oposição, estaria desregulando o equilíbrio financeiro retirando dinheiro da SEC, o que caracteriza claramente uma disputa no campo político e não educacional.

Os Programas Experimentais para o Curso Primário (SEC, 1950b), são um documento com 93 páginas divididas em: Objetivos Específicos do Curso Primário e Sugestões Didáticas que por sua vez são divididas em: Técnicas de Expressão (Linguagem oral, Linguagem escrita, Composição, Ortografia, Desenho, Trabalhos Manuais, Canto Orfeônico); Conhecimentos Gerais Aplicados: Geografia e História; Iniciação matemática e
Educação Física. Cada um dos tópicos traz: Objetivos Gerais; Objetivos específicos e Práticas ou Sugestões didáticas.

Como já enfatizado, nosso objetivo precípuo é destacar as áreas e conhecimentos inerentes à formação cultural e artística. Dessa forma, manteremos nosso foco nas Técnicas de Expressão: Desenho e Trabalho Manuais. Na primeira parte sobre os objetivos educacionais de cada série, encontramos as seguintes menções referentes aos conhecimentos artísticos.

$\left[1^{o}\right.$ ano] ter aprendido a usar tinta de parede para expressões pessoais mediante a pintura; ser capaz de modelagem de memória baseada em percepção recente $e$ de recortes simples de criação pessoal [...] ter aprendido a participar com prazer nos cantos e rondas da sua classe; [2 ${ }^{\circ}$ ano] ter progredido na expressão pessoal pelo desenho, a pintura, a modelagem $e$ o recorte; [...] ser capaz de sentir pela audição de repertório de música selecionado para sua idade; ser capaz de reconhecer o Hino Nacional e o da Bandeira; ser capaz de participar com prazer no canto de rondas, canções e hinos ensinados à sua classe; [ $3^{\circ}$ ano] ter tornado a sua representação pelo desenho mais visual, do que lógico, pelo uso da perspectiva, etc.; ter se iniciado a usar o desenho como instrumento para outras atividades, como os trabalhos manuais; ter aperfeiçoado a sua capacidade de expressão e criação pessoal pelo desenho e pela modelagem; [...] ter apreendido a apreciar o valor da contribuição artística e cientifica no processo de engrandecimento nas nações; [...] ter progredido em sua capacidade de apreciação musical e ter aperfeiçoado a sua capacidade de participação no canto coral; $\left[4^{\circ}\right.$ ano] ter sido iniciado na compreensão do valor de formas esteticamente melhores da língua; [...] ter sido iniciado na literatura dramática; [...] ter adquirido uma noção dos elementos técnicos mais rudimentares do desenho e de pintura como as noções de valor, de perspectiva aérea, e ter adquirido, não só mais capacidade de expressão pessoal pelo desenho, como igualmente, ter adquirido a idéia bem clara de que, nesse domínio, é necessário procurar o 
esteticamente melhor; ser capaz de atividades manuais úteis e expressivas, conhecendo as técnicas rudimentares de impressão com cartolina, batatas, $e$, sobretudo, o linóleo; [...] ter sido iniciado no hábito de seguir interessadamente o movimento cientifico, artístico, social $e$ político da nação; [...] ouvir com atenção $e$ prazer músicas selecionadas e participar dos cantos corais de sua classe, conhecendo os hinos patrióticos e tendo adquirido um elevado sentido de respeito pelo Hino Nacional e da Bandeira. (SEC, 1950b, p 48).

Observando os objetivos dos Programas, constata-se uma posição que remete ao mesmo tempo às práticas tradicionais de ensino de arte e às práticas renovadoras, embora, como afirma Rosa (2005, p. 31), os "caminhos trilhados pela Pedagogia da Escola Nova e suas influências no ensino de arte apontam uma série de controvérsias", que para a pesquisadora vão do uso parcial das teorias de Dewey, muitas vezes reduzidas à livreexpressão, ou de interpretações pessoais das correntes modernistas, como no caso de Mário de Andrade. Nesse sentido, seria de se esperar que a proposta de Pilotto apresentasse ainda uma certa linha apontada como tradicional, especialmente na questão do canto orfeônico, ainda associado ao ensino das tradições cívicas. Por outro lado, o ensino de desenho priorizava o ensino geométrico e técnico, o que se vê parcialmente na proposta de Pilotto, bem como a inclusão da modelagem e das técnicas de gravura nos trabalhos manuais, que retiram dessas atividades a perspectiva de iniciação ao trabalho e de divisão por sexos.

No Programa para desenho são destacados como objetivos gerais para o ensino primário cinco pontos:

1 - Exercício das forças de criação do espírito infantil. 2 - Desenvolvimento sensorial e motor e desenvolvimento do sentido de observação. 3 - Iniciação ao conhecimento dos elementos técnicos do desenho e da pintura: perspectivas, valores, etc. 4 - Desenvolvimento da sensibilidade estética. 5 - Desenvolvimento da capacidade de usar o desenho como um instrumento para a vida prática (SEC, 1950b, p. 30).
Para Pilotto, o desenho no ensino primário tem por objetivo o domínio de uma certa técnica, observada nas sugestões didáticas que incluem o ensino do desenho de memória, desenho de observação, perspectiva, desenho rítmico e métrico, técnicas de pintura e desenho de silhueta, que visam tanto o exercício do olhar, como também, o domínio da gramática específica da linguagem visual. A utilização do desenho como ferramenta vem das concepções do ensino do desenho, como preparação para o trabalho como proposto por Rui Barbosa no final do século XIX, que aparecem em exercícios de decoração e caligrafia artística. Já a natureza expressiva do desenho, enquanto possibilidade de linguagem para a criança, vem das correntes oriundas do modernismo das artes, percebidas em exercícios como: desenho espontâneo, desenho de imaginação e de interpretação e desenho de fantasia. Observa-se que a concepção de ensino de desenho de Pilotto passa também pela observação de obras e de artistas, como indicado no seguinte exercício: manuseio de álbuns de "artistas célebres" com reproduções de "pintura mundial". (SEC, 1950b, p. 31-32).

É recomendada a criação de um ambiente específico para as aulas de desenho, bem como a variação desse espaço com aulas ao ar livre, com o uso de cavaletes, além da manutenção de exposições dos trabalhos da turma.

Eram indicados quatro livros para o professor de desenho que seriam: $O$ desenho racional na Escola, de Ferdinand Liendux; Pedagogia Científica, de Maria Montessori; Reflexões sobre o ensino de dezenho, Revista de Pedagogia (Argentina, set. 1939) e por fim El tesouro del Maestro - $5^{\circ}$ volume. Especificamente para o terceiro ano, foi indicada a obra de Artus Perrelet, com a seguinte descrição:

O ensino da perspectiva será iniciado como uma correção dos desenhos da primeira parte, não sistemática, deste programa. Cabe completa-lo com lições especiais posteriores, sobre a perspectiva do circulo $e$, também, mesmo agora mas ordenadamente, a perspectiva da retas, dada de modo prático, segundo, por exemplo, a processuação de Perrelet (SEC, 1950b, p. 32).

Sobre a inclusão dos conceitos de Perrelet, na Revista de Pedagogia (mar. 1960, p. 1), Pilotto comenta que a obra Desenho ${ }^{4}$ era extremamente 
rara em âmbito local e que a seu pedido, a professora Odette de Mello Cid, do Serviço de Assistência Técnica da SEC, realizou uma síntese das propostas da educadora. Não fica claro no artigo se o texto de Cid foi feito no período de gestão de Pilotto ou se na época da publicação do periódico, visto que a professora foi uma das responsáveis pelo ensino de desenho e pintura para professores em cursos de aperfeiçoamento do Instituto de Educação, a partir da gestão de Pilotto na SEC. Sobre o método de Perrelet, o intelectual fez a seguinte observação:

O método de Perrelet repousa, todo ele, sobre a preocupação, de ordem fundamental, de levar a criança a uma profundidade de vida interior que ela, depois, exprimirá pelo desenho [...] Uma rica vivência dos fatos e das significações que vão, dali, a pouco, exprimir-se numa linha, num ponto, num esboço. Desse modo, uma linha que talves se tenha lançado um pouco grosseiramente no papel ou no quadro, estará alimentada por um rico processo de vivências anteriores [...] Perrelet quer animar a linha mais simples ou grosseira de um significado tão profundamente sentido e tão rico quanto possivel. Na verdade de, um simples ponto, por exemplo, deve ser compreendido como o sinal que fica [...] que diz solenemente: $E$ aqui! [...] É um sinal! Para conseguir que a criança chegue a isso, Perrelet se empenha em descobrir, acordes com a psicologia e a compreensão infantil os processos mais engenhosos, utilizando jogos e brinquedos, levando a criança a fazer ela mesma, experiências musculares e emocionais, até que ela chegue a sentir e provar interiormente o sentido daquilo que ela vai desenhar. (PILOTTO, mar. 1960, p. 1).

Ao colocar o método de Perrelet no terceiro ano do ensino primário, Pilotto demonstra que sua compreensão do desenho enquanto expressão da criança não deveria seguir os caminhos da livreexpressão todo o tempo, mas que a partir de um certo amadurecimento da criança, ela deveria ser iniciada em aspectos mais formais do desenho, compreendendo sua gramática e chegando a um certo apuro técnico e a um exercício do olhar. No texto de Cid sobre a perspectiva do círculo, indicado nos Programas Experimentais, encontramos as seguintes atividades sugeridas.

a) Observar as deformações do círculo unindo o polegar ao índice, colocando-o bem à vista, isto é, sem deformação [...] Depois fazer coloca-lo em posição horizontal e fazer notar que é visivel apenas o polegar como uma linha [...] Esse exercício, bem motivado, deve ser acompanhado de comentários inteligentes, pois a linguagem precisará o pensamento. b) Utilizar um quadrado de papelão sobre o qual se recorta um círculo, que, móvel gira em torno de um eixo, através do espaço vazio deixado pelo mesmo círculo recortado. A medida que o circulo gira, nota-se a deformação evidenciada pela silhueta [...] c) Fazer observar em objetos (tigelas, canecas, etc) colocadas acima, abaixo e sobre a linha do horizonte, as diversas elipses formadas. Depois passar ao desenho das mesmas. (CID, mar. 1960, p. 7).

Analisando a síntese da obra de Perrelet feita por Cid, nota-se o caráter de manual de seu texto, com indicações de atividades, que são completadas por ilustrações. 


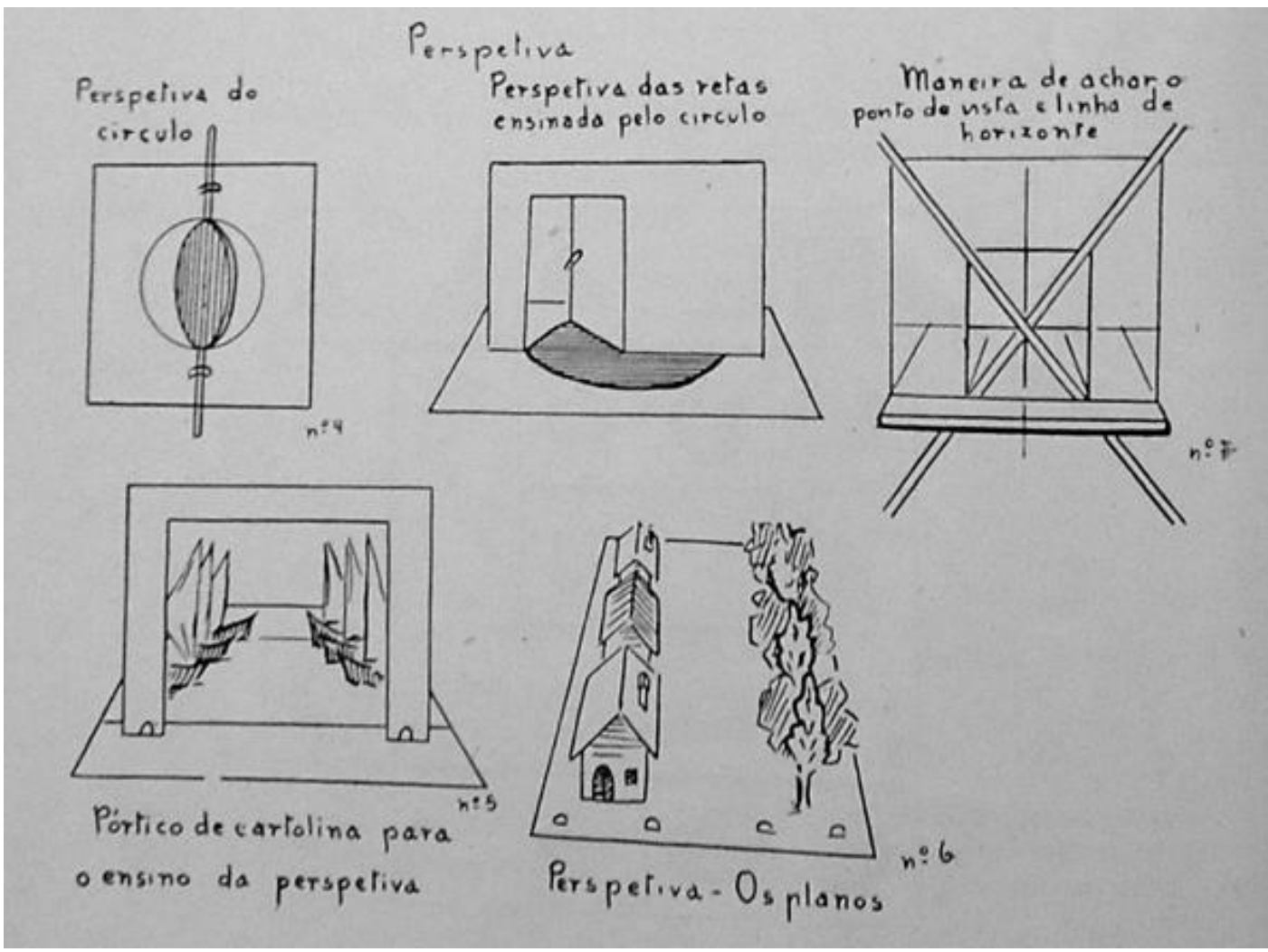

FIGURA 1: PERSPECTIVA, REVISTA DE PEDAGOGIA, MAR 1960, P. 6.

Diferentemente da obra de Perrelet, que discute os aspectos psicológicos e teóricos do desenvolvimento infantil e da linguagem visual, temos uma proposição em termos práticos, que evidencia a proposta de Pilotto de dois tipos de professores, aqueles que teriam a função de líderes, como é o caso da Professora Odette Cid, que possivelmente conhecia a obra de Perrelet em seus aspectos conceituais e realizou uma síntese, destinada a segunda categória de professores, estabelecida por Pilotto, a daqueles que atuariam na escola. De acordo com Ana Mae Barbosa, o conceito de desenho de Perrelet visa a integração do corpo e da mente, experiência e raciocínio, gesto e visão, vida e símbolo, indivíduo e meio ambiente, sujeito e objeto em uma declaração autêntica de educação e arte. Ainda para autora, Perrelet coordenou de forma clara a ideia de arte pela arte criticando o desenho como um fim único e baseado em modelos.

$O$ que ela pretendia mostrar era a possibilidade de integração do desenho na educação de modo a tornar possivel a exploração desse meio especializado através da experimentação com os elementos que constituem sua linguagem. Ao mesmo tempo, insistia que tal experimentação e exploração constituíram um hábito de pensar apropriado a experiências de natureza diferente das verbais. Isto se aproxima das afirmações de Dewey em "Affective Thought" [...] Enfaticamente contrária à "segregação das atividades", "departamentalização da vida" e "compartimentação de interesses", Perrelet, assim como Dewey, defendia a teoria darwiniana de educação como um desenvolvimento contínuo começando das funções inferiores para as superiores em integração (BARBOSA, 1989, p. 68-69).

A abordagem da gramática do desenho foi evidenciada por Pilotto especialmente para as crianças mais velhas como observamos nos Programas Experimentais a partir da terceira série, e na sua experiência na coluna de Gurizada, vamos desenhar (1944), na qual o intelectual publicou uma série de artigos - dezenove no total - que visavam incentivar as crianças no desenho. Ao analisarmos essa experiência, constatamos que Pilotto possuía duas abordagens diferentes, para as crianças pequenas valorizava a questão da expressão, sem discutir sua construção formal, ao passo que para as crianças mais velhas indicava formas de melhorar seu desenho e incentivava o exercício de observação 
da natureza e de obras de arte.

Outro ponto a ser destacado na opção realizada por Pilloto, de ensinar a criança aspectos mais formais do desenho, vem das categorias impostas ao campo da arte e da educação ${ }^{5}$, que colocam em oposição o ensino de desenho na "Escola Tradicional" e na "Escola Nova", como observado no livro da pesquisadora Rosa Iavelberg, sobre o ensino do desenho.

Na escola tradicional, o meio ditava a regra de acomodação da criança a modelos para aprender a desenhar, por intermédio da repetição de exercícios de treino de habilidades, a questão técnica ocupava vasta área no que se entendia por criação em desenho, com ênfase no produto. $\mathrm{Na}$ escola renovada ${ }^{6}$ o desenho é compreendido como atividade expressiva, livre e natural da infância, com centro no indivíduo, exploração livre de materiais $e$ técnicas com foco no processo - e não no produto - e no desenvolvimento do potencial criador (IAVELBERG, 2006, p. $13)$.

O posicionamento de Iavelberg sobre o desenho na escola tradicional e na escola nova é uma constante em pesquisadores sobre métodos e metodologias sobre o ensino de $\operatorname{arte}^{7}$. O que colocaria Pilotto, partindo dessa grade de análise, em uma posição intermediária entre as práticas tradicionais e ditas renovadas. Embora seja necessário relativizar esses posicionamentos que criam uma oposição completa entre o ensino do desenho nesses dois momentos do campo educacional, como duas figurações ${ }^{8}$ opostas. Pois como afirma Vieira (2001, p. 1-2) refletindo sobre a homogeneização de termos como escolanovismo, educação renovada, escola ativa e educação nova, seriam expressões que não representam a pluralidade de ideias do Movimento pela Escola Nova, prejudicando sua compreensão histórica e a diversidade dos discursos, em prol de generalizações. Nesse sentido não seria correto afirmar a tensão entre práticas tradicionais e renovadas nos métodos empreendidos por Pilotto, mas que estes se caracterizam por suas opções teóricas, incluindo a leitura de Montessori, que se coloca contra as práticas da livre-expressão, e de Pestalozzi, que afirma a importância do desenho como exercício do olhar.

$\mathrm{Na}$ obra Pedagogia Científica, citada nos programas como referência para o ensino de desenho, Montessori faz a seguinte observação sobre seu método:

Não ensinamos desenho fazendo desenhar, mas oferecendo a oportunidade de adestrar-se com os instrumentos de expressão. E penso isto constitui uma autêntica contribuição para o desenho livre, muito melhor do que esses encorajamentos a desenhos monstruosos e incompreensiveis (MONTESSORI, 1965, p. 266).

Por outro lado, para Pestalozzi o desenho estaria associado à tendência natural da criança à imitação e à ideia de jogo, propondo que o desenvolvimento do desenho seja feito a partir da observação do real, mais no sentido de superar a abstração por meio da materialidade do que propriamente como uma forma de expressão. Na obra Cartas sobre educación infantil, Pestalozzi (2001. p. 96-97) menciona a capacidade do desenho de desenvolver a percepção e diz que como um botânico consegue analisar uma flor em aspectos que passam despercebidos a um leigo, uma pessoa que copia a natureza passará a observá-la com mais atenção. Para o autor, a criança "acostumada a olhar para tudo com exatidão, [...] formará dos objetos correntes uma impressão mais correta do que de outra que nunca ensinaram a olhar bem para saber o que reproduzido em um desenho" (PESTALOZZI, 2001. p. 96-97, [tradução nossa]). ${ }^{9}$

No sentido de valorização da observação, cabe analisar outras das referências citadas nos Programas para o ensino de desenho. No livro $E l$ tesouro del Maestro (1937) de Sthieler, no capítulo a Enseñanza del dibujo o autor remete-se às concepções de Rosseau que para ele, no século XVIII, com sua obra Emílio, ou, da educação (1999) seria o primeiro educador a sugerir um arquivo de desenhos infantis e a propor que a criança deveria desenhar sem a interferência de um professor, especificamente criticando a cópia de modelos. Para Rousseau, a criança não deveria ter contato com um "[...] professor de desenho, que só lhe daria imitações para imitar, e só faria desenhar sobre desenhos: quero que ele tenha como único mestre a natureza, e como modelo apenas os objetos" (ROUSSEAU, 1999, p. 170). Nesse sentido para Rosseau era

[...] pela observação do modelo, a criança acabaria por descobrir as imperfeições de 
seu desenho espontâneo, Rousseau não pretendia o desenho de memória e sim o desenho de observação fiel à natureza. Propunha, então, que professor e aluno desenhassem livremente, e que os desenhos produzidos fossem organizados $e$ emoldurados de forma a permitir a observação da experiência e a geração da aprendizagem (ANTONIO, 2008, p. 35).

Rosseau é colocado como um dos autores fundamentais de Pilotto em sua formação no Centro de Cultura Pedagógica, nesse sentido a valorização da observação do natural, já era um princípio discutido por Pilotto desde suas primeiras incursões sobre a educação.

Para Ferdinand Liénaux ${ }^{10}$ (1943, p. 3-5), outro autor recomendado nos Programas, o ensino de desenho segue duas tendências, a realista e a idealista. A tendência realista é caracterizada como puramente objetiva, nela o objetivo é representar o mundo tal como aparece na realidade, o desenho seria nessa perspectiva um instrumento que através de suas deformações (perspectiva) e ilusões de ótica buscaria representar a realidade. Ao passo que a tendência idealista possui um caráter sentimental, na qual o mundo é representado através do "temperamento de artista". O desenho seria a interpretação da concepção estética do desenhista. Assim, enquanto no desenho realista tem-se a "materialização da imagem visual" o desenho idealista seria a "expressão de um sentimento ou de uma impressão". O desenhista, no primeiro caso, desenha aquilo que vê ou que sabe, e no segundo caso, aquilo que sente ou interpreta através da sensibilidade. Embora aponte essa dicotomia, para Liénaux, ambas tendências se completam: "O primeiro é formador, pois apela para a observação e para o raciocínio. Serve de base para o segundo, que é o reflexo da personalidade artística, na maioria dos casos, fruto de uma educação prévia".

Nesse sentido, a obra de Liénaux se propõe a ensinar o caráter realista do desenho que, na opinião do autor, permitiria que o aluno pudesse posteriormente se expressar. Nesse sentido, sua proposta supera o aspecto da livre-expressão, na qual o educador deve pouco intervir na obra do aluno, mas em seu método deve-se partir do desenho racional, que tem por fim "ensinar a comparar, e medir e a exprimir as proporções, direções e valores, apelando para a observação racionada" em uma lição sintetizada pelo autor no conceito de que "não se desenha bem, aquilo que não se conhece bem" (LIÉNAUX, 1943, p. 5). Percebemos em Liénaux uma estreita consonância com Montessori e Pestalozzi, no sentido de utilizar o desenho como um exercício de olhar, tendência percebida nos Programas Experimentais, que propõem uma forma mais livre no jardim de infância, com o aprofundamento técnico com o avanço no ensino primário, refletida pela inclusão da obra de Perrelet no quarto ano, como uma correção das formas livres executadas anteriormente.

Ainda conforme Liénaux (1943, p. 17-18), no ensino primário o desenho deverá passar por quatro graus ou etapas. $\mathrm{Na}$ primeira temos o desenho espontâneo e de expressão livre, incluindo aos poucos o desenho do natural (por meio da observação). O segundo grau seria a passagem do desenho simbólico ao desenho racional, classificado como um programa transitório, no qual os desenhos do natural e de memória estariam mais presentes. O terceiro grau seria o da observação refletida, definida como a representação analítica baseada nos aspectos da observação e das técnicas de desenho; e por fim o quarto grau, no qual teríamos a aplicação do desenho e a inclusão da estética. Ao analisarmos o programa do ensino primário, observamos que, de certa forma, os graus estabelecidos por Liénaux foram distribuídos em cada uma das séries. Como já citamos, na experiência da coluna Gurizada, vamos desenhar Pilotto apresenta uma concepção que se aproxima a de Liénaux, no sentido do exercício livre para crianças menores e a valorização da observação para as crianças maiores, como podemos perceber na citação dos trechos da coluna, como o publicado em 4 de junho de 1946, que apresenta uma análise realizada por Pilotto dos desenhos enviados pelas crianças:

[...] Lizete de Ferviles: Diga-me: Todas as árvores do quintal de sua casa são iguais? Pois, no seu desenho parece que são iguais. Faça-me o favor de mandar, para a próxima secção, só o desenho daquelas quatro árvores. Mas veja se o desenho fica mais ou menos parecido com cada árvore. Hebe Pinheiro Lima: Gostei muito, muito mesmo de seu desenho, minha amiguinha Hebe. Aquela cerca, aqueles carneiros, aquelas galinhas, tudo muito puro. Como se chama o seu cachorro? [...] João Antonio Xavier: O seu João Antonio, foi o melhor de todos os trabalhos, considerando a sua idade: 5 anos. Você é um colosso! 
(PILOTTO, 4 jun. 1946, p. 4, grifo nosso).

No mesmo artigo faz a seguinte proposição de um exercício de observação:

Agora não é ainda para você desenhar. É só para ver. Pegue uma xícara. Ponha-a em cima da mesa. Olhe bem: veja que o lado em que entra luz na sala a xícara está mais clara. Há um ponto bem brilhante; agora vá acompanhando a claridade nessa xícara; vá reparando como a sombra vai aumentando, para o lado contrário à luz. Agora compare a sombra da xícara com a sombra que ela faz em cima da mesa. Veja qual é a mais escura. Veja a parte de dentro da xícara: também lá há partes de sombra e de luz. Compare a sombra de dentro da xícara com a de fora. Você agora é capaz de desenhar uma xícara, indicando essas diferenças na iluminação? (PILOTTO, 4 jun. 1946, p. 4).

Conforme observamos nos comentários e instruções de Pilotto, percebemos sua correspondência com os autores indicados por ele nos programas, e mesmo com autores com os quais o intelectual tinha como referência, como é o caso de Pestalozzi. Nesse sentido, Pilotto afasta-se dos autores ligados à livre-expressão, por seu método prescindir já no ensino primário de uma certa diretividade das atividades de desenho, ponto que para alguns teóricos como Mario de Andrade, Herber Read e Lowelfld, não caberia para o desenvolvimento do desenho na infância.

Para os trabalhos manuais, os Programas preveem atividades que envolvem a modelagem e a gravura. Diferentemente dos programas habituais da disciplina, que se destinavam à formação geral e à formação ao trabalho. São citados como pontos dos trabalhos manuais:

1 - Exercícios e estímulo à capacidade de criação do espírito infantil. 2 Desenvolvimento neurológico e muscular da criança. 3 - Desenvolvimento da iniciativa, de hábitos de ordem, de cooperação e do desejo de perfeição. 4 Capacidade para atividades manuais úteis na vida diária (SEC, 1950b, p. 32).

No primeiro e segundo anos são sugeridas especialmente as atividades de modelagem que devem ser espontâneas e não seguir modelos prontos. Conforme as orientações, essas atividades podem ser também estimuladas por atividades oriundas de outras disciplinas, bem como de fábulas, contos e histórias. Para Pilotto, assim como para Gentile e Pestalozzi, os trabalhos manuais devem ser atividades de formação do espírito e apesar da valorização dos aspectos expressivos, a técnica não deveria ser abandonada, conforme observamos nas recomendações feitas nos Programas:

Considere o professor, que na escola elementar, o trabalho manual é um fator de formação, de portanto mais valor as reações que ele determina no educando de que ao resultado material em si mesmo. Como no desenho, permita e incentive a livre elaboração. Considere o ainda, técnica de expressão. Motive-o sempre, e use-o como motivação (SEC, 1950b, p. 33).

Na obra El tesouro Del Maestro (1937), recomendada como bibliografia de apoio ao professor, temos descrito que o sentido dos trabalhos manuais para a "pedagogia moderna" deve pautar-se pela autonomia do aluno, autonomia que levaria ao autodesenvolvimento e a autorrepresentação. Conforme o autor do livro (STHIELER et all, 1937, p. 121), apesar dos grandes pedagogos terem feito referência à importância do impulso criativo para educação, poucos referenciaram as práticas - provavelmente $o$ autor estivesse se referenciando aos trabalhos manuais - que seriam um ponto importante para o desenvolvimento da criança por relacionar a investigação científica com a prática escolar. Assim, para o autor "não é suficiente que a criança jogue e se ocupe com os objetos; a escola deverá perseguir também que a ação se converta em aprendizado, e se possível em autoeducação" (STHIELER el all, 1937, p. 123, [tradução nossa] ${ }^{11}$ ).

O princípio da autoeducação foi um conceito corrente na concepção de Pilotto, aplicado em sua formação inicial, no Centro de Cultura Filosófica e no Centro Cultural de Pedagogia, e valorizado para a formação dos professores por meio da criação dos Centros de Cultura, que buscariam através da autoeducação e do autoditatismo ampliar a formação da cultura geral e artística.

Para o quarto ano, os Programas sugerem a inclusão de técnicas de impressão ou gravura, se aproximando de um movimento do próprio campo 
artístico que iniciava uma maior exploração da gravura enquanto técnica artística. No mesmo período encontramos menções de um curso de gravura promovido pela SEC e ministrado por Poty Lazarroto, colaborador, conjuntamente com Pilotto, da revista Joaquim. Apesar de não ser destinado a professores, mas ao "publico interessado", o curso ocorreu paralelamente aos cursos de especialização de professores. Na matéria Curso sobre técnica de Gravura, são descritos os objetivos da SEC em realizar tal curso:

[...] constitui uma ótima oportunidade aos nossos artistas pintores, que desejarem adquirir os conhecimentos técnicos da gravura, aliás modalidade artística ainda pouco desenvolvida no Brasil. Eis porque está-se convidando os alunos de desenho e pintura das escolas, tanto Oficial como as particulares, bem como candidatos avulsos. Patrocinando este curso, a Secretaria de Educação e Cultura além de reconhecer os méritos de Poty, visa estimular estudo da gravura no Paraná (GAZETA DO POVO, 21 jul. 1950, p. 3).

A história da arte no Paraná considera a iniciativa do curso de gravura promovida pela SEC como uma das primeiras ações que visavam difundir a técnica da gravura no meio local, consideração que indica que sua inclusão nos Programas demonstra uma interação entre os campos da arte e da educação, incentivado pela atuação política da SEC.

\section{Considerações Finais}

Com a indicação ao cargo de Secretário da Educação e Cultura, Pilotto pode confrontar suas experiências no campo educacional e artístico realizadas nas décadas de 1930 e 1940, com a realidade dos grupos escolares da capital e do interior do Estado. E apesar destas não serem a "Escola Serena", concebida em sua primeira obra pedagógica - Prática da Escola Serena (1946), percebe-se que o papel da arte e da cultura continuam sendo fundamentais em sua estratégia pedagógica.

Nos Programas Experimentais fica evidente a posição de Pilotto sobre o ensino de desenho, no qual tanto o aprendizado técnico como a expressão da criança eram pressupostos educacionais, concepção que o aproxima das ideias de Dewey para o ensino de arte. E em relação aos trabalhos manuais, a inclusão da gravura como uma das atividades prescritas na disciplina acompanha o movimento do campo artístico local, no qual a gravura começa a ser explorada como forma de expressão arttística.

Nesse sentido, Pilotto articula conjuntamente três campos distintos: artístico, educacional e político através de suas ações e obras, procurando assim definir seu projeto educacional que tem na arte um princípio formativo.

\section{Notas}

1 Conforme Veiga: "No Brasil Republicano, as belas artes estiveram presentes nos currículos das escolas primárias, escolas normais e secundárias" (2003, p. 412).

2 No início do século XX tem início um movimento de renovação no campo artístico, que marca o abandono dos cânones acadêmicos preestabelecidos em favor da valorização da expressão individual do artista. Como exemplo dos movimentos renovadores, temos $\mathrm{o}$ Expressionismo alemão, com forte inspiração da arte primitiva. No mesmo período, pesquisas sobre o desenvolvimento infantil trouxeram novas perspectivas sobre a produção de arte infantil. Os reflexos no ensino de arte fortaleceram a opinião de que a arte não poderia ser ensinada, constituindo-se uma expressão do indivíduo. De forma ampla, esse movimento passou a ser denominado de livre-expressão (OSINSKI, 2001).

3 Herbert Read, que defendia a expressão infantil e a centralidade da arte no processo educativo. Para o autor o ensino da arte era composto pela articulação de três atividades distintas: a autoexpressão, a observação e a apreciação.

4 Conforme Barbosa (1989) a obra de Perrelet, $O$ desenho a serviço da educação, foi o único livro publicado pela autora e teve duas edições, sendo a segunda de 1930, publicada juntamente com a edição brasileira.

$5 \mathrm{Na}$ década de 1950, não podemos falar de um campo do ensino de arte no contexto brasileiro. Apenas na década de 1980, pode-se considerar que este campo tornou-se autônomo dos campos da educação e da arte, embora mesmo agora tenha uma autonomia relativa.

6 Apesar de considerarmos a classificação de Escola Tradicional e Escola Renovada, como simplistas, concordamos com a autora na questão de que os 
autores ligados ao Movimento pela Escola Nova e ao Ensino de arte partem da perspectiva de compreender a arte infantil em suas especificidades, elegendo a expressão como ponto fundamental do trabalho em arte na infância.

7 Obras de autores como: Ferraz e Fusari (1993 e 1999), Martins (1998) e Rosa (2005), tratam de forma generalista a pedagogia tradicional, a pedagogia nova ou renovada e a pedagogia tecnicista, baseando-se em posições hegemônicas dos discursos de cada movimento, visto que tais obras não têm um caráter de história do ensino de arte, mas se destinam a discutir aspectos metodológicos e suas concepções sobre as pedagogias citadas, tratam de uma breve contextualização para abordarem por fim as pedagogias para o ensino da arte estruturada a partir da Proposta Triangular de Ana Mae Barbosa na década de 1980. Mas por se constituírem em referências para a formação de professores de arte e para os cursos normais suas concepções acabam por cristalizar uma memória do ensino de arte no Brasil.

8 Outra noção operatória utilizada nesse trabalho é o de figuração ou configuração de Norbert Elias. Para o autor as figurações "são formadas por grupos interdependentes de pessoas organizadas em estados e não por indivíduos singulares independentes". (ELIAS 1999, p. 31).

9 "Acostumbrada como está a fijarse en todo con exactitud, [...] formará de los objetos corrientes una impresión mas correcta que otro a quien nunca han ensenãdo a mirar bien lo que ve para saberlo reproducir en un dibujo" (PESTALOZZI, 2001. p. 96-97).

$10 \mathrm{Na}$ edição encontrada do livro $O$ desenho racional na Escola (1943), Ferdinand Liénaux é apresentado como Inspetor do ensino de desenho na Bélgica. A obra não indica o ano da edição original.

11 "Sin embargo, nos es suficiente que el niño juegue y se ocupe con los objetos; la escuela deberá perseguir también que la acción se convierta en ensenãnza, y si es posible, en autoeducación".

\section{Fontes}

A Escola Pestalozzi que Fracassou. Diário da Tarde. Curitiba: 17 mar. 1950, p. 1 e 6.
CID, Odette de M. O método de Madame Artus Perrelet para a iniciação ao Ensino Desenho. Revista de Pedagogia. Curitiba: mar. 1960, ano IV, $\mathrm{n}^{\circ} 1$. p. 2-10.

LIÉNAUX, Ferdinand. O desenho racional na Escola. Porto Alegre: Ed. Globo, 1943.

MONTESSORI, Maria. Pedagogia Científica: A descoberta da Criança. São Paulo: Ed. Flamboyant, 1965.

PILOTTO, Erasmo. Prática de Escola Serena. Curitiba: 1946;

Gurizada, vamos desenhar! Diário da Tarde. Curitiba: 4 jun. 1946, p. 4.

1952

. A Educação é Direito de Todos. Curitiba:

A educação no Paraná: Síntese sobre o ensino público elementar e médio. Rio de Janeiro: INEP, 1954.

O método de Madame Artus Perrelet para a iniciação ao Ensino Desenho. Revista de Pedagogia. Curitiba: mar. 1960, ano IV, nº 1. p. 12.

Autobiografia. (org.) Denise Grein Santos. Curitiba: Editora UFPR, 2004.

PESTALOZZI, Johann Heinrich. Cartas sobre educaciòn infantil. Org. Cabanas, José M. Quintana. Madrid: Editorial Tecnos, 2001.

ROUSSEAU, Jean. J. Emílio, ou, da educação. São Paulo: Martins Fontes, 1999.

SEC. Programas Experimentais para o Jardim de Infância. Curitiba, 1950a.

SEC. Programas Experimentais para o Ensino Primário. Curitiba, 1950b.

STIEHLER, G. et all. El tesouro del Maestro: Metodologia del dibujo, trabajos manuales, labores femeninas, economia doméstica, música y gimnasia. Buenos Aires: Editorial Labor, 1937, tomo quinto. 
ANTONIO, Ricardo Carneiro. Arte na educação: o projeto de implantação de Escolinhas de Arte nas escolas primárias paranaenses (décadas de 1960 1970). Curitiba: 2008. Tese (Doutorado em Educação). Setor de Educação, Universidade Federal do Paraná.

BARBOSA, Ana Mae. Recorte e Colagem: A influência de John Dewey no ensino da arte no Brasil. São Paulo: Autores Associados: Cortez, 1989.

BORDIEU, P. A sociologia de Pierre Bourdieu. São Paulo: Olho d'Água, 1994.

As regras da arte: gênese e estrutura do campo literário. São Paulo: Companhia das Letras, 1996.

A economia das trocas simbólicas. 5 ed., São Paulo: Perspectiva, 2004.

Questões de Sociologia. Lisboa: Ed. Fim de século, 2006.

BOTELHO, Jordana Stella. Jardins da infância paranaenses: do Programa de Experiências de 1950 ao Regimento e Planejamento de Atividades de 1963. Dissertação apresentada ao Programa de Pósgraduação em Educação, da Universidade Federal do Paraná. Curitiba: 2011.

ELIAS, Norbert. Introdução à Sociologia. Lisboa: Estampa Ed., 1999.

FERRAZ, M. H. C. de T. e FUSARI, M. F. de R. Metodologia do Ensino de Arte. São Paulo: Ed. Cortez, 1999.
IAVELBERG, Rosa. O desenho cultivado da criança: práticas e formação de educadores. Porto Alegra: Ed. Zouk, 2006.

OSISKI, Dulce. Arte, História e Ensino - Uma trajetória. São Paulo: Cortez, 2001.

READ, Herbet. A educação pela arte. São Paulo: Martins Fontes, 2001.

ROSA, Maria Cristina. A formação de professores de arte: Diversidade e complexidade pedagógica. Florianópolis: Insular. 2005.

SILVA, Rossano. A Arte como princípio educativo: Um estudo sobre o pensamento educacional de Erasmo Pilotto. Curitiba: 2009. Dissertação (Mestrado em Educação). Setor de Educação, Universidade Federal do Paraná.

VEIGA, Cynthia Greive. Educação Estética para o povo. In.: FARIA FILHO, Luciano Mendes, LOPES, Eliane Marta Teixeira e VEIGA, VEIGA, Cynthia Greive. 500 anos de educação do Brasil. Belo Horizonte: Autêntica, 2003, p. 399-422.

VIEIRA, Carlos Eduardo. Erasmo Pilotto e a Escola Nova no Paraná. In: V Congresso Ibero Americano de Historia de la Educación Latino Americana, 2001. Anais do V Congresso Ibero Americano de Historia de la Educación Latino Americana. p. 110. Costa Rica.

Educação e modernidade no projeto formativo de Erasmo Pilotto. In: IV Congresso Brasileiro de História da Educação, 2006, Goiânia. Anais do IV Congresso Brasileiro de História da Educação. Goiânia: Universidade Católica de Goiás, 2006. v. 1. p. 1-10.

\section{Sobre o autor:}

Rossano Silva: Doutorando em Educação e Mestre em Educação na Linha de História e Historiografia da Educação pela UFPR. Especialista em Ensino da Arte pela Faculdade de Artes do Paraná e graduado em Licenciatura em Desenho pela Escola de Música e Belas Artes do Paraná (2001). Professor titular da UFPR no departamento de expressão gráfica.

Recebido em 30/05/2014

Aprovado em 11/08/2014 